\title{
Guest Editorial: Are "alternative" stem cell sources still alternative in the new era?
}

\author{
Junya Kanda ${ }^{1} \mathbb{D}$
}

Received: 15 May 2019 / Accepted: 21 May 2019 / Published online: 28 May 2019

(c) Japanese Society of Hematology 2019

Two to three decades ago, the only available stem cell sources for allogeneic hematopoietic stem cell transplantation (HSCT) were human leukocyte antigen (HLA)-matched related or unrelated bone marrow or peripheral blood stem cells. At that time, it was not possible to perform allogeneic HSCT for patients without HLA-matched donors. More recently, transplantation from HLA single locus-mismatched related and unrelated donors as an alternative stem cell source has been performed increasingly, with acceptable outcomes; however, overall survival using stem cells from such donors has been inferior to that in matched transplantation. As reviewed by Dr. Koji Kawamura [1], the use of lowdose anti-thymocyte globulin has improved outcomes of one locus-mismatched unrelated bone marrow transplantation, which are now nearly comparable to those of HLA-matched unrelated bone marrow transplantation.

After Dr. Eliane Gluckman et al. performed the first cord blood transplantation (CBT) for patients with Fanconi anemia [2], the cord blood unit has been used as an immediately accessible alternative stem cell source for both adult and pediatric allogeneic HSCT. The less stringent requirement for HLA matching under standard graft-versus-host disease (GVHD) prophylaxis and the easy access to these cord blood units attracted many transplant physicians to this new alternative stem cell source. Although the high incidence of graft failure and infection had been the major obstacles for CBT, the use of double cord blood units and improvements in conditioning regimens and GVHD prophylaxis have improved CBT outcomes. Incorporating HLA allele matching, including the HLA-C locus and CD34 cell dose,

Junya Kanda

jkanda16@kuhp.kyoto-u.ac.jp

1 Department of Hematology and Oncology, Graduate School of Medicine, Kyoto University, 54 Kawaharacho, Shogoin, Sakyo-ku, Kyoto 606-8507, Japan as well as the total nucleated cell counts in the cord blood selection process has led to better neutrophil engraftment and survival. Outcomes of CBT have been particularly good in Japan, and more than 1000 CBTs per year are now being performed. As Dr. Hisashi Yamamoto outlines [3], outcomes of CBT have improved significantly and are nearly comparable to those of HLA 8 allele-matched unrelated transplantation. However, the engraftment rate remains unsatisfactory. As Dr. Ko K. Maung and Dr. Mitchell E. Horwitz describe in this issue, various umbilical cord blood expansion techniques have demonstrated shorter periods from transplantation to engraftment and high engraftment rates [4]. The only unsolved problem is the risk of viral infections in CBT.

The risk of GVHD in transplantation from related donors with multiple HLA mismatches under standard GVHD prophylaxis has been unacceptably high. Various GVHD prophylaxes, such as the use of anti-thymocyte globulin, alemtuzumab, ex vivo $\mathrm{T}$ cell depletion, and other techniques have been developed, but strong immune suppression inevitably increases the risk of infection and relapse. Dr. Junichi Sugita provides an overview of how post-transplantation cyclophosphamide has achieved the best results and worldwide popularity. In this method, alloreactive $T$ cells are efficiently removed, whereas $T$ cells against pathogens and viral agents are retained [5]. Although a higher risk of relapse associated with this regimen must be considered, especially for patients with high-risk diseases, the lower transplantrelated mortality far outweighs the disadvantage of relapse risk. This method has now been tested as GVHD prophylaxis for HLA-matched related and unrelated transplantation.

Most studies to date have compared outcomes using different stem cell sources, but we now observe nearly comparable outcomes irrespective of stem cell source. The boundary between the first choice of donor, HLA-matched donor, and other "alternative" sources is disappearing. An 
alternative stem cell source will become, or has already become, one of the first choices in allogeneic HSCT.

\section{Compliance with ethical standards}

Conflict of interest The author declares no competing financial interests.

\section{References}

1. Kawamura K. Effect of antithymocyte globulin on HLA-mismatched unrelated transplantation. Int J Hematol. 2019. https:// doi.org/10.1007/s12185-019-02597-y.

2. Gluckman E, Broxmeyer HA, Auerbach AD, Friedman HS, Douglas GW, Devergie A, et al. Hematopoietic reconstitution in a patient with Fanconi's anemia by means of umbilical-cord blood from an HLA-identical sibling. N Engl J Med. 1989;321:1174-8.

3. Yamamoto H. Single cord blood transplantation in Japan; Expanding possibilities of CBT. Int J Hematol. 2019. https://doi. org/10.1007/s12185-019-02672-4.

4. Maung KK, Horwitz ME. Current and future perspectives on allogeneic transplantation using ex vivo expansion or manipulation of umbilical cord blood cells. Int J Hematol. 2019. https://doi. org/10.1007/s12185-019-02670-6.

5. Sugita J. HLA-haploidentical stem cell transplantation using posttransplant cyclophosphamide. Int J Hematol. 2019. https://doi. org/10.1007/s12185-019-02660-8.

Publisher's Note Springer Nature remains neutral with regard to jurisdictional claims in published maps and institutional affiliations. 